\title{
OS GÉNEROS DAS PROVAS ACADÉMICAS: entre discurso académico e discurso científico
}

\author{
Maria Aldina Marques \\ CEHUM-Universidade do Minho \\ https://orcid.org/0000-0003-3263-1977
}

\section{RESUMO:}

É consensual a afirmação de Bakhtine de que falamos por géneros. A adoção deste postulado torna indispensável considerar o estatuto teórico do género e a área de atividade verbal a que se agrega, isto é, o tipo de discurso em que tem lugar. Por outras palavras, para analisar a linguagem em uso é necessário discutir o conceito de género de discurso, o que define um género, quais os parâmetros a considerar. O presente trabalho pretende, a propósito de um evento académico designado provas de agregação, determinar, descrever e explicar a categorização de um dos discursos, um género institucionalmente denominado Lição. Esta categorização é feita a partir da análise de um corpus e das perceções dos usuários sobre este género, no quadro de uma análise dos discursos.

PALAVRAS-CHAVE: discurso académico; discurso científico; género discursivo; lição; provas de agregação.

\section{THE GENRES OF AGGREGATION EXAM: \\ between academic discourse and scientific discourse}

\section{ABSTRACT:}

Bakhtine's statement that we speak by discourse genres is consensual. The adoption of this postulate leads to consider the theoretical status of discursive genre and the area of verbal activity in which it is included, that is, the type of discourse in which it takes place. In other words, to analyze the language in use, it is necessary to discuss the concept of discourse genre, to 
find out what defines a genre or which parameters to consider for the analysis. Within an academic event called Provas de Agregação (aggregation exam), the present work aims to determine, describe and explain the categorization of one of the speeches part of this event, an institutional genre called Lição (Lesson). Attention to empirical discourses and all the contribution of research to their categorization direct scientific discussion to topics such as the delimitation of genres and types of discourse. This academic communicative event under study has characteristics that are important for the analysis of this problematic. This research, based on a corpus, analyses the users' perceptions about the genre Lição, within a theoretical framework of discourse analysis.

KEYWORDS: academic discourse; scientific discourse; discursive genre, Lesson, Aggregation Exam.

\section{Provas de agregação: entre géneros e tipos de discurso}

Deve-se a Bakhtine (1984) a afirmação de que falamos por géneros, chamando assim a atenção para a dimensão social do uso da linguagem. $\mathrm{O}$ modo como os falantes percebem essa categoria varia em função das circunstâncias em que a interação acontece, mas também em função do conhecimento específico que cada um possui do género em causa.

$\mathrm{Na}$ perspetiva de uma análise linguística dos discursos (Marques, 2015), o conceito de género é central e tem sido objeto de pesquisa e discussão, não apenas quanto ao seu estatuto, em conexão com uma área de atividade verbal ou tipo de discurso, e um específico quadro teórico de análise (Adam \& Heidmann, 2004; Adam, 2011; Maingueneau, 2014; Charaudeau, 2015, entre outros), mas também quanto às realizações empíricas na sua variedade e heterogeneidade, a que Kerbrat-Orecchioni \& Traverso (2004) se referem como promessas de género. ${ }^{1}$

\footnotetext{
${ }^{1}$ Como princípio categorizador dos discursos, o género discursivo tem consequências metodológicas ao nível da própria constituição dos corpora de análise.
} 
Mas na comunidade científica atual nem todos os géneros têm a mesma visibilidade. Se o discurso científico e o discurso académico estão entre os mais estudados (Swales, 1990, Hyland 2002, Boch \& Rinck, 2010, entre outros), nem todos os géneros que os integram têm recebido a mesma atenção investigativa. Entre os mais analisados estão, no discurso científico, o artigo científico, que se tornou um género prototípico (Flottum, 2006) e, no discurso académico, as dissertações de mestrado e doutoramento, que suscitam conclusões similares de saliência (Rinck, 2011). ${ }^{2}$

Propomo-nos analisar um género particular do discurso académico, a lição, integrada num evento comunicativo compósito, as provas de agregação (a partir de agora provas), as últimas provas públicas prestadas por um professor universitário português, necessárias para habilitar a um concurso para professor catedrático, como consta do Decreto-Lei n. ${ }^{\circ}$ 239/2007, de 19 de Junho.

Dessas provas, constituídas por apresentação e discussão, perante um júri, de uma Relatório de disciplina, do curriculum vitae do candidato e de uma lição com a duração de 60 minutos, selecionámos esta última como objeto de estudo. O objetivo primeiro é determinar as características do género lição, nas perceções dos candidatos a essas provas a partir das características dos discursos que constituem o nosso corpus. Para isso, colocámos a hipótese de categorização da lição como um género híbrido do discurso académico, convocando contextos diversos, em função do duplo estatuto, de docente e de examinando, assumido pelo locutor. Este hibridismo, segunda hipótese, mostra-se ainda a um outro nível, na medida em que a lição faz parte de dois tipos de discurso, o discurso académico e o discurso científico, neste último caso pelas relações de similaridade que estabelece com os parâmetros do artigo científico e o estatuto de investigador do locutor. Acresce, ainda, e será a terceira hipótese, que, apesar das constrições sobre o género, decorrentes da sua inserção em provas académicas, muito regulamentadas, a ritualização do género é fraca.

De acordo com o Decreto-lei supracitado, as provas são constituídas pela "apreciação e discussão do currículo do candidato",

${ }^{2}$ Distingo discurso científico e discurso académico de acordo com a "finalidade primeira de cada tipo de discurso" que "pode sintetizar-se como fazer ciência, aprender ciência [...], respetivamente." (Marques, no prelo), assumindo também que as fronteiras são porosas. 
“apresentação, apreciação e discussão de um relatório sobre uma unidade curricular, grupo de unidades curriculares, ou ciclo de estudos, no âmbito do ramo do conhecimento ou especialidade em que são prestadas as provas" e "um seminário ou lição sobre um tema dentro do âmbito do ramo do conhecimento ou especialidade em que são prestadas as provas". Os dois primeiros documentos são apresentados previamente, enquanto o terceiro é apresentado sob a forma de um sumário pormenorizado de uma lição (ou seminário) a desenvolver oralmente, em 60 minutos, na presença do júri (art. 8. ${ }^{\circ}$, alínea c).

A presente análise está ancorada num quadro enunciativopragmático dos discursos, um posicionamento teórico que privilegia a linguagem em uso e os discursos como práticas sociais de comunicação verbal e assume, por conseguinte, a centralidade teórica e metodológica dos conceitos de tipo e de género de discurso.

A atenção aos discursos empíricos e todo o contributo da investigação para a sua categorização direcionam a discussão científica para tópicos como a delimitação dos géneros e dos tipos de discurso, uma questão que também agora nos ocupa, a propósito deste evento comunicativo académico, que consideramos apresentar características importantes para a análise dessa temática.

A recolha dos dados para a constituição do corpus foi feita na internet, especificamente nos repositórios abertos das diferentes universidades públicas portuguesas. Mas, se as provas de agregação são públicas, nem sempre acontece o mesmo com os discursos produzidos para e durante as provas. $^{3}$ De facto, nem todos os materiais estão disponíveis e, quando estão, predomina o acesso restrito. ${ }^{4}$ Ainda quanto aos dados empíricos disponíveis, a lição é sobretudo disponibilizada sob a designação de sumário pormenorizado da lição, de acordo com os preceitos legais. Tal designação poderia fazer supor que se trata de um género diverso da lição, mas a análise dos dados mostra que se trata, na maior parte dos

\footnotetext{
${ }^{3} \mathrm{O}$ que sobressai é um certo secretismo, relativamente às características de género da lição, que a dificuldade de acesso e a inexistência de investigação sobre a área a partir das ciências da linguagem tornam ainda mais evidente.

${ }^{4}$ Como exemplo, no Repositório Aberto, da Universidade Aberta há 12 lições, das quais três estão em acesso aberto e 9 em acesso restrito.
} 
casos, da totalidade da lição e não apenas de um sumário. ${ }^{5}$ E pese embora as especificidades de um sumário pormenorizado, ${ }^{6}$ quando de tal se trata, há, de facto, características estruturais e metadiscursivas que são comuns e nos interessam sobremaneira. Tendo em conta essa diversidade de designações, sumário pormenorizado e lição, foram selecionados para análise os doze discursos abaixo indicados, elaborados entre 2007 e 2018 e apresentados em universidades públicas portuguesas. A delimitação temporal dos dados recolhidos, tem por base a última alteração jurídica das provas, o Decreto-lei acima referido.

\begin{tabular}{|c|l|l|l|l|}
\hline & Autor/data & Área científica & Universidade & páginas \\
\hline 1 & AJR, 2011 & C. farmacêuticas & U. Coimbra & 13 \\
\hline 2 & APB, 2014 & C. da Linguagem & U. Évora & 16 \\
\hline 3. & HV, 2008 & Sociologia & U. Porto & 11 \\
\hline 4. & CP, 2011 & C. da Educação & U. Porto & 13 \\
\hline 5. & MID, 2009 & Sociologia & U. Porto & 18 \\
\hline 6. & JB, 2014 & C. da Educação & U. Aveiro & 65 \\
\hline 7. & MHS, 2008 & C. da Comunicação & U. Minho & 34 \\
\hline 8. & FP, 2011 & C. Educação & U. Aveiro & 38 \\
\hline 9. & MB, 2012 & Ensino a distância & U. Aberta & 48 \\
\hline 10. & JC, 2008 & C. da Comunicação & U. Beira Interior & 56 \\
\hline 11. & FPC, 2009 & Matemática & U. Aberta & 80 \\
\hline 12. & MRC, 2018 & C. da Comunicação & U. Minho & 41 \\
\hline
\end{tabular}

\section{Das provas de agregação ao género discursivo lição}

O género em análise é institucionalmente designado como lição e faz parte, como apontado, de um evento comunicativo compósito. Esta complexidade tem diferentes explicações. São, por

\footnotetext{
${ }^{5}$ Regista-se aqui esta dissonância sem posterior análise, reconhecendo-se, embora, o interesse de estudar a divergência de géneros na divergência /convergência da designação „sumário pormenorizado“ e „lição“. Apenas damos conta dessa variabilidade pela interferência na seleção dos discursos que constituem o corpus. ${ }^{6} \mathrm{O}$ corpus que constituímos, mostra, por esta razão, uma enorme disparidade de páginas nos discursos selecionados.
} 
um lado, provas constituídas por várias interações verbais, escritas e orais, realizadas em tempos e espaços diversos, e agregando, por outro, intervenientes com estatutos sociais e comunicativos também diversos, quer considerando as várias interações, quer o decurso de cada interação.

\subsection{Do dispositivo legal às construções discursivas}

A informação primeira e fundamental sobre as provas é, como se disse, de natureza jurídica e concerne às condições reguladoras da atribuição do título de agregado, no Decreto-Lei n. ${ }^{\circ}$ 239/2007, de 19 de Junho, acima referido, e que vem substituir decretos anteriores ${ }^{7}$. No seu preâmbulo, os objetivos das provas são definidos em termos de capacidades científicas a serem testadas e atestadas, especificamente, "a capacidade de investigação e a aptidão para dirigir e realizar trabalho científico independente".

É sobre a disposição legal na sua globalidade que se debruçam alguns estudos. É o caso de Cunha (2007) que discute os objetivos e conteúdos destas provas, a partir da necessidade de determinar os critérios a considerar pelos membros do júri na avaliação do candidato. Um outro documento, antecedendo a publicação do decreto acima referido, o diploma de 14 de outubro de 2005 (que altera a forma de avaliação pelo júri, acabando com o sistema de avaliação secreta, por bolas preta e branca) contribui para a reflexão sobre o tema:

$\mathrm{Na}$ agregação é analisado o curriculum científico, técnico e pedagógico, além de uma lição, verdadeiro ponto alto em que deverão ser respeitadas as regras pedagógicas, mas com particular ênfase nas descobertas e contributo para o progresso científico da área em questão, síntese do valor como investigador e pedagogo.

(PROJECTO DE LEI N. ${ }^{\circ}$ 175/X, (aditamento ao Decreto-Lei n. ${ }^{\circ} 216 / 92$, de 13 de Outubro)

\footnotetext{
7 “A atribuição do título académico de agregado pelas universidades portuguesas não é regulada por diploma próprio, mas sim por analogia com o regime aplicado, na vigência do Decreto-Lei $\mathrm{n}^{\circ}$ 132/70, de 30 de Março, ao recrutamento de professores extraordinários, regulado pelo Decreto n ${ }^{\circ} 301 / 72$, de 14 de Agosto".
} 
É, pois, nas entrelinhas que podem descobrir-se alguns dos parâmetros enquadradores dos tipos e géneros em causa nas provas, avaliados em função de "regras pedagógicas", mas também, e sobretudo, do "contributo para o progresso científico". ${ }^{8} \mathrm{E}$, por isso, se privilegia nos discursos, em termos dos papéis sociais do locutor, os papéis de investigador e de docente, a que acresce um outro papel, que aqui sobreleva, o de candidato-examinando, pois é da aferição do seu valor naqueles dois domínios que se trata.

\subsection{Heterogeneidade dos géneros e categorização genérica da lição}

Os parâmetros de género permitem categorizar os discursos empíricos, não como condições necessárias e suficientes, mas como um conjunto de características que podem ser mais ou menos prototípicas. É com os novos conceitos de genericidade e efeito de genericidade que Adam (2012: 19, nomeadamente) enquadra em termos teóricos o dinamismo inerente ao conceito e parâmetros definidores do género, concebido como um conjunto de potencialidades atributivas. A instabilidade assim teorizada opõe-se à conceção do género como uma categoria previamente definida, estática e fechada, sobredeterminando os discursos empíricos. Como sublinha o autor, o objetivo é pôr em evidência o facto de estes parâmetros serem, justamente, possibilidades de categorização a que cada discurso empírico se conforma de modo mais ou menos próximo, reconhecendo-se, assim, a este nível, a heterogeneidade constitutiva dos discursos (Filliettaz \& Grobet, 1999). Outros autores, como Maingueneau (2014) e Charaudeau (2015), na sequência, todos, do contributo inicial de Bakhtine (1984), afirmam a necessidade de os parâmetros elencados serem tomados não como condições necessárias e suficientes, mas como características que podem ser mais ou menos centrais na definição da categoria ou categorias em causa e manifestados de modo diverso em cada

\footnotetext{
${ }^{8}$ As propostas de Cunha (2007) são concordantes, elencando 4 vertentes tradicionais: (1) Maturidade e qualidade científica; (2) Reconhecimento Internacional; (3) Inserção Institucional; (4) Maturidade e qualidade pedagógicas.
} 
discurso empírico, ${ }^{9}$ dependendo a determinação dos parâmetros de género quer das condições de produção impostas pelas práticas sociais, pela situação de comunicação, quer das propriedades dos textos ou discursos.

A mesma indeterminação de fronteiras caracteriza os tipos de discurso. Maingueneau (2014) lembra que um tipo de discurso é constituído por uma rede de géneros, mas é uma rede desigual, heterogénea, em que alguns são prototípicos, como o género artigo científico (Fløttum, 2006), no discurso científico, e outros são menos prototípicos, híbridos mesmo, enquanto partilham características de dois tipos de discurso distintos. Trata-se, aliás, de um fenómeno mais amplo, decorrente da "liquidez" das fronteiras nas sociedades modernas. A rede de géneros não é privativa, antes é mais ou menos partilhada por áreas de atividade verbal, de que são exemplo saliente as inter-relações entre o discurso político e o discurso mediático (Marques, 2013). ${ }^{10}$

Este reenquadramento teórico sustenta a presente análise e é, por sua vez, reforçado pelos resultados obtidos.

\subsubsection{Lição como denominação do género.}

Dos primeiros diplomas, que antecederam o Decreto-Lei $\mathrm{n}^{\circ}$ 239/2007 de 19 de Junho, ficou aí, explicitamente, a designação e a determinação do tema, na seguinte formulação: "lição síntese, escolhida pelo candidato, sobre um problema dentro do âmbito da disciplina ou grupo de disciplinas para que foi aberto o concurso", agora adaptado a novas designações a que acresce a introdução de um outro objeto, o seminário, como prova possível, em alternativa à designação tradicional de lição: “...um seminário ou lição sobre um tema dentro do âmbito do ramo do conhecimento ou especialidade em que são prestadas as provas, e sua discussão". ${ }^{11}$

\footnotetext{
${ }^{9}$ Tendo em conta esta instabilidade essencial, deve lembrar-se que os parâmetros a considerar na categorização dos géneros de discurso não são um conjunto fixo nem homogéneo.

${ }^{10}$ É dessa hibridação que se fala, quando se adota, por exemplo, o termo infotainment.

${ }^{11} \mathrm{O}$ único exemplo do corpus em análise indicia que não há efetivamente alteração face à lição. A designação adotada decorre da sua integração numa unidade curricular de mestrado. Mas põe em relevo esta ligação estreita a uma vertente pedagógica.
} 
Pese embora tal alteração, a tradição havia já consolidado a restrição a um tema proposto no relatório sobre uma unidade curricular/disciplina (e, em alguns casos, a permanência mesmo da designação lição de sintese, como em HV, 2008, FPC, 2009 e AJR, 2011).

Para além destas particularidades, as perceções dos falantes dão conta de outras indefinições e variações, que condicionam as características de género da lição. De facto, o estatuto da lição no conjunto das provas é uma das preocupações mais frequentes e, por isso, sobressai nos discursos uma vertente metadiscursiva explícita, que ocupa a primeira secção do plano de texto, onde se discutem os objetivos e a temática, a partir da própria designação como lição, bem como os estatutos sociais/académicos e comunicativos dos interlocutores. Dando-lhe subtitulações diferentes - nota prévia, preâmbulo, introdução -, o locutor procede, na verdade, a um juízo avaliativo do discurso que está a construir, justificador das opções tomadas, quanto ao assunto da lição. ${ }^{12}$ Esta argumentação decorre de o Decreto-Lei prever a escolha do tema pelo candidato, dentro do ramo ou especialidade das provas:

(1) a escolha do assunto a tratar na lição [...] pressupõe que o candidato tenha, não apenas conhecimentos suficientemente aprofundados sobre o tema, mas também, experiência científica sólida que os sustente. (AJR, 2011: 4)

(2) A nossa opção [...] tem sido uma das áreas de reflexão e pesquisa mais recente por parte da docente (HV,2008: 3).

(3) Todas estas questões, além da óbvia relevância matemática, têm também interpretações físicas de clara importância para as aplicações. (FPC, 2009)

Nestes excertos, exemplificativos do corpus em análise, cada locutor pretende evidenciar o bem-fundado da escolha do tema da lição, com argumentos que decorrem sobretudo da sua própria

\footnotetext{
${ }^{12}$ Esta reflexão encontra-se quer das lições, quer dos sumários pormenorizados, no corpus em análise.
} 
investigação. Quando efetivamente explicitadas, são, portanto, questões científicas e não pedagógicas que ditam a escolha. Mas trata-se, simultaneamente de uma negociação explícita do género e das suas características, pela verbalização de um contrato comunicativo (Charaudeau, 1983; Maingueneau, 1998) a estabelecer com os interlocutores, os membros do júri.

Ainda que a argumentação realizada se apoie na imagem de investigador do locutor, o conteúdo temático da lição é ditado, maioritariamente, pelos conteúdos programáticos da unidade curricular alvo do Relatório, de acordo com uma tradição que, como assinalado, o decreto-lei em vigor não prevê. ${ }^{13} \mathrm{O}$ tema da lição é enquadrado numa unidade curricular, é localizado no conjunto dos seus conteúdos programáticos:

(4) A lição enquadra-se, mais propriamente, na fase final do desenvolvimento da unidade curricular, quando os estudantes já estejam [sic] familiarizados... (FP, 2011)

Há, no entanto, um afastamento relativamente às características de uma aula. Desde logo na denominação. A consulta do Dicionário da Língua Portuguesa Contemporânea, mostra que, se aula e lição podem ser interligadas a partir de uma relação de sinonímia, a segunda apresenta outros sentidos que não são partilhados pela primeira. Mais ainda, o significado de "lição" de que estamos a tratar é aí explicitamente individualizado como "preleção proferida, perante um júri, por um docente universitário como prova de concurso ao grau de professor agregado". Ora, não há aqui nenhuma referência à situação de aula, envolvendo alunos e professor; bem pelo contrário, os interlocutores considerados são um docente universitário na função de candidato e o júri das provas.

Pese embora esta argumentação, a relação direta a uma "aula" é explicitamente reclamada em alguns dos discursos analisados

(5) A aula teórica número 7 enquadra-se na unidade curricular de "Educação para a saúde I" do plano de estudos da licenciatura

\footnotetext{
${ }^{13}$ Mas deve reconhecer-se que a indicação de um seminário em alternativa a uma lição traz para a discussão este enquadramento "pedagógico" (cf. Nota de rodapé 11).
} 
em enfermagem na Universidade de Évora. É assegurada no $2^{\circ}$ semestre do $1^{\circ}$ ano. Tem a duração de 120 minutos. Nesta lição é apresentada a segunda parte da aula, com duração de 60 minutos." (JB, 2014)

Saliente-se, contudo, que se trata de uma identificação pretendida, que não tem em conta diferenças contextuais relevantes. De um aspeto dessa dissonância, que nem sempre é verbalizada, mas é considerada, dá conta o excerto seguinte:

(6) O tempo estabelecido por lei para a apresentação da lição, obriga-nos a fazer opções criteriosas na escolha e na relevância a dar aos diferentes aspectos do tema a tratar. (AJR, 2011: 4)

Desenham-se já algumas características que evidenciam a heterogeneidade do género. Os locutores constroem um lugar compósito que conjuga estatutos sociais e comunicativos não coincidentes e plurais.

$\mathrm{Na}$ determinação das características de género o mais importante são os participantes, uma asserção a tomar em interrelação com o conceito de contexto, que, sendo central na construção dos discursos, tem que ser entendido como um conjunto de representações, de saberes, dos interlocutores, pois só desse modo interferem na construção discursiva (van Dijk, 2012, KerbratOrecchioni, 2002, Koch, Morato \& Bentes, 2011, Micheli, 2006, nomeadamente). Deste conceito de contexto, decorre uma diluição da distinção entre espaço interno e externo ao discurso, e, por conseguinte, entre parâmetros externos e internos, que comparticipam da sua construção, a partir do crivo dos saberes dos interlocutores.

O estatuto comunicativo do locutor da lição é complexo. A integração do género num evento académico de provas atribui ao locutor o papel de candidato-examinando, mas a especificidade da lição, tal como é entendida pelos usuários, impõe a conjugação do papel social-académico de professor, in absentia, com o de examinando, in praesentia, com implicações óbvias ao nível da construção discursiva global. 
A lição integra, por tradição, vários alocutáriosdestinatários ${ }^{14}$ coletivos, hierarquizados, com perfis completamente diversos.

Nos discursos em análise, a designação de lição leva a que, explicitamente, os alunos sejam alocutários-destinatários, quer porque está tematicamente integrada num ponto dos conteúdos programáticos de uma unidade curricular lecionada pelo locutor enquanto docente, quer pela identificação sinonímica entre lição e aula já referida. Mas existe um outro alocutário coletivo, destinatário principal e presente, constituído pelo conjunto dos elementos que integram o júri, parte integrante da situação de comunicação. ${ }^{15}$

A determinação deste destinatário principal é, por conseguinte, sujeita a flutuação. O locutor pode escolher e eleger os alunos ou os elementos do júri. O exemplo seguinte é elucidativo quanto a essa possibilidade de escolha.

(7) Optou-se por elaborar uma lição pedagogicamente dirigida para os alunos do Segundo Ciclo de Estudos em Sociologia, usando uma estratégia didáctica com recurso a material ilustrativo e actividades demonstrativas e não pela modalidade de uma comunicação científica dirigida ao restante público-alvo destas Provas de Agregação, isto é, o painel de especialistas presentes na sua avaliação.» (CRP, 2011:2).

Note-se que em (7), o locutor procede a uma hierarquização explícita dos alocutários, reclamando para si, em consequência, a imagem de docente em detrimento da imagem de investigador. Mas mesmo aí, se em termos metadiscursivos os alunos podem ser selecionados como destinatário coletivo primeiro, todas as dimensões da organização da lição mostram, especificamente, que na verdade o destinatário principal é outro, o júri das provas. É aliás frequente que, de forma explícita, o locutor se mostre como especialista em diálogo com especialistas:

\footnotetext{
${ }^{14}$ Sobre esta distinção teórica ver Ducrot (1984).

${ }^{15}$ Dado o caráter de provas públicas, existe ainda um outro destinatário coletivo, a audiência, na posição de participante espectador.
} 
(8) tem como objetivo apresentar um conjunto de estudos realizados por mim própria que considero contribuírem significativamente para o desenvolvimento dos estudos da memória, como campo inter e transdisciplinar. (MRC, 2018)

(9) A lição sobre o tema "e.raizes_redes": eixos | arquiteturas | contextos" inscreve-se em reflexões orientadas para uma ação à escala global, reflexões essas que visam a análise do impacto das tecnologias da comunicação no âmbito dos processos de uma mudança civilizacional (de ordem social, política, económica, cultural) nas sociedades, contemporâneas. $(\mathrm{MB}, 2012)$

(10) O objectivo principal deste trabalho é passar em revista resultados de análise matemática relativos a existência, unicidade e diversos aspectos do comportamento das soluções, com especial enfoque para questões e problemas em cuja investigação estivemos, em alguma altura, envolvidos e sobre os quais fizemos alguma contribuição para a literatura. (FPC, 2009: 3)

O locutor, no estatuto de candidato à realização das provas de agregação, elabora o seu discurso segundo a imagem que constrói dos seus diversos alocutários-destinatários e da situação comunicativa em que o vai realizar. A lição obriga, pois, nas perceções dos usuários, a correr o risco de assumir a heterogeneidade discursiva, desde logo como heterogeneidade enunciativa, acrescida, neste caso, da heterogeneidade que decorre de um discurso "contextualmente desdobrado", ancorado em dois géneros distintos, que convocam estatutos diversos, o de examinando, a realizar uma prova, o de professor, a realizar uma aula, dois géneros do discurso académico, a que acresce o de investigador que apresenta os resultados da sua investigação, o que faz com que o discurso 
académico se entrelace com o discurso científico. ${ }^{16}$ Como vimos, o locutor explicitamente convoca essa sua vertente investigativa, que se mostra também no plano de texto da lição, próximo do plano de texto do artigo científico. O índice, característico da lição, dá conta dessa proximidade:

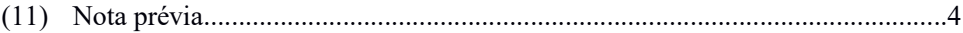

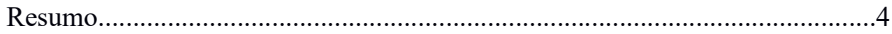

1. Estudos da memória em tempos de pós-verdade.............................................6

2. Memória social e assimetria simbólica......................................................

3. Os "acontecimentos" da história da humanidade e da história nacional.......14

4. As "personalidades" da história da humanidade e da história nacional........24

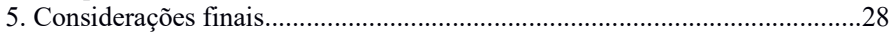

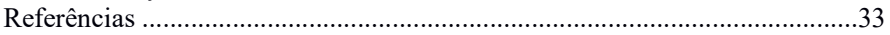

(MRC, 2018)

Saliente-se, ainda, e de acordo com Fløttum (2006), que as referências bibliográficas constituem uma marca de género do artigo científico, e assumem aí funções diversas (Swales, 1990, Marques, no prelo). Ora, em todos as lições analisadas, o processo de "referenciamento", englobando a referência (simples ou multirreferência, hetero e autorreferência) e a citação, é obrigatório e todas terminam com uma lista extensa de referências bibliográficas, impossível de justificar como bibliografia recomendada própria de uma aula, mas necessária num quadro global de apresentação da investigação, em que o locutor constrói o seu lugar ou, como diz Swales (1990), define o seu espaço de investigação. No contexto das provas, e do papel académico de candidato, o locutor afirma a sua "maturidade científica", no modo como organiza a lição.

16 A consideração das relações de lugares dos interlocutores (lugares sociais e discursivos), os objetivos e a natureza deste evento discursivo académico, em particular, condicionam a orientação dialógica, o posicionamento enunciativo, a orientação argumentativa do discurso e, claro, a construção da referenciação. 


\section{Conclusões}

Uma possível ritualização do género lição sobredeterminado pelas constrições que os quadros jurídico e académico impõem não se verifica. Há uma variação substancial, que decorre das opções de cada locutor, do modo como percebe o que em termos da análise linguística dos discursos se define como características genéricas da lição, integrando umas provas de agregação.

$\mathrm{Na}$ área vasta, compósita e heterogénea do discurso académico, em que primeiramente se integra por fazer parte de provas académicas, a lição assume, enquanto género, características específicas, de hibridismo, dentro do discurso académico, fruto da tensão discursiva entre o papel de docente e o papel de examinando assumidos pelo candidato. A mesma tensão se faz sentir entre o discurso académico e o discurso científico, consequência da assunção pelo locutor de um outro papel, o de investigador. E a lição aproxima-se, por força desta constrição, do artigo científico.

Das perceções dos falantes, que aqui foram analisadas, sobressai a dimensão científica da lição. Mesmo quando se afirma explicitamente a sua natureza pedagógica, são as capacidades científicas do locutor que este sente serem testadas. E por isso é previsível que a lição seja publicada como artigo científico (cf. JB, 2014, publicado em Martins, 2019).

Ser docente universitário é mais uma capacidade em avaliação no conjunto das provas, isto é, a par da maturidade científica, a sua maturidade pedagógica, avaliável e avaliada para além de uma aula específica.

Finalmente, a situação comunicativa dá saliência à função de candidato-examinando. É para os elementos do júri que o locutor fala, em relação interacional assimétrica, que o coloca em posição baixa face à posição alta dos examinadores.

No plano teórico, sobressai a pertinência do conceito de efeito de genericidade, capaz de explicar a heterogeneidade e instabilidade que caracterizam a lição enquanto género discursivo, mas sobressai também a necessidade de estender essa abordagem aos tipos de discurso, áreas de atividade verbal igualmente instáveis e heterogéneas. 


\section{REFERENCIAS}

ADAM, J.-M. Discursivité, généricité et textualité. Distinguer pour penser la complexité des faits de discours. Recherches , $\mathrm{n}^{\circ}$ 56, 2012, p. 9-27.

. La linguistique textuelle. Introduction à l'analyse textuelle des discours. Paris: Armand Colin, 2011.

ADAM, J.-M. \& HEIDMANN, U. (2004). Des genres à la généricité. L'exemple des contes (Perrault et les Grimm). Langages 153, 2004, p. 62-72.

BAKHTINE, M. Esthétique de la Création Verbale. Paris: Gallimard, 1984.

BOCH F. \& RINCK, F. Pour une approche énonciative de l'écrit scientifique. Lidil [En ligne], 41, 2010, p. 5-14. Disponível em: http://lidil.revues.org/3004. Acessado em 31/08/2013.

CHARAUDEAU, P. La situation de communication comme fondatrice d'un genre: la controverse. In: MONTE, M. \& PHILIPPE, G. (dir), Genres et textes : déterminations, évolutions, confrontations. Lyon: Presses universitaires de Lyon, 2015, p. 49-57.

CHARAUDEAU, P. Langage et Discours: eléments de sémiolinguistique, Paris, Hachette, 1983.

CUNHA, P. (2007). Agregação: lei e interpretação. Fronteira de qualidade universitária, 2007. Disponível em: http://www.snesup.pt/cgi-bin/artigo.pl?id=EEAyyAZkkEEFfeWthm. Acessado em 12/04/2020.

DUCROT, O. Le dire et le dit. Paris: Les Editions de Minuit, 1984.

FLØTTUM, Kjersti. The typical research article does it exist?, In: SALMI, EIJA SUOMELA \& DERVIN, Fred (eds.), Perspectives interculturelles et interlinguistiques sur le discours académique. Crosscultural and Crosslinguistic Perspectives on Academic Discourse (ebook). Department of French Studies, The University of Turku, Finland, 2006. Disponível em: https://www.utupub.fi/bitstream/handle/10024/69214/BOOKacademi $\mathrm{c} \% 20$ discourse.pdf? sequence $=1$ \&isAllowed $=\mathrm{y} . \quad$ Acessado em 03/01/2020. 
HYLAND, K. Authority and invisibility: Authorial identity in academic writing. Journal of Pragmatics, 34, 2002, p. 1091-1112.

KERBRAT-ORECCHIONI, C. (2002). Système linguistique et ethos communicatif. Cahiers de praxématique 38, 2002. Disponível em: http://praxematique.revues.org/540. Acessado em 31/08/2006.

KERBRAT-ORECCHIONI, C. \& TRAVERSO, V. Types d'interactions et genres de l'oral. Langages 153, 2004, p. 41-51.

KOCH, I. MORATO, E. \& BENTES, A. Ainda o contexto: algumas considerações sobre as relações entre contexto, cognição e práticas sociais na obra de Teun van Dijk. ALED 11 (1), 2011, p. 79-91

MAINGUENEAU, D. Discours et analyse du discours. Paris: A. Colin, 2014.

MAINGUENEAU, D. Analiser les textes de communication. Paris: Dunod, 1998.

MARQUES, M. A. Para uma análise linguística dos discursos. A heterogeneidade enunciativa como princípio ordenador da investigação. Revista de Filoloxía Galega 16, 2015, p.107-121.

MARQUES, M. A. A. Politique, humour et campagne électorale. Les enjeux d'une politique spectacle. Mots. Les langages du Politique, 101, 2013, p.61-75. Disponível em: http://mots.revues.org/21146. Acessado em 03/11/2019.

MARQUES, M. A._Vozes da ciência: discurso científico e enunciação._no prelo).

MARTINS, I. P. (org), Percursos de investigação em educação no CIDTF: um itinerário pelas lições de agregação. Aveiro: Universidade de Aveiro, 2019.

MICHELI, R. Contexte et contextualisation en analyse du discours : regard sur les travaux de T. Van Dijk. Semen 21, 2006. Disponível em: http://semen.revues.org/1971. Acessado em 14/02/2017.

RINCK, F. Former à (et par) l'écrit de recherche. Quels enjeux, quelles exi gences? Le Français aujourd'hui 174, 2011, p.79-89.

SWALES, J. Genre analysis: english in academic and research settings. Cambridge, Cambridge University Press, 1990. 
VAN DIJK, T. Discurso e contexto: uma abordagem sociocognitiva (Trad. Rodolfo Ilari). São Paulo: Contexto, 2012.

Recebimento em: 27/10/2019 Aceito em: 09/03/2020 